\title{
A 'Fresh Eyes' Look at Improving the Effectiveness of Engineering Group Design Projects
}

\section{Kyte, Adam}

http://hdl.handle.net/10026.1/9617

\subsection{0/ened.2013.00009}

Engineering Education a Journal of the Higher Education Academy Informa UK Limited

All content in PEARL is protected by copyright law. Author manuscripts are made available in accordance with publisher policies. Please cite only the published version using the details provided on the item record or document. In the absence of an open licence (e.g. Creative Commons), permissions for further reuse of content should be sought from the publisher or author. 


\section{A 'Fresh Eyes' Look at Improving the Effectiveness of Engineering Group Design Projects}

\section{Adam Kyte}

To cite this article: Adam Kyte (2013) A 'Fresh Eyes' Look at Improving the Effectiveness of Engineering Group Design Projects, Engineering Education, 8:1, 81-97

To link to this article: http://dx.doi.org/10.11120/ened.2013.00009
(2) 2013 J. Davies, The Higher Education
Academy

曲 Published online: 15 Dec 2015.

Submit your article to this journal $\pi$

Џlll Article views: 131

Q View related articles ¿ 


\title{
A 'Fresh Eyes' Look at Improving the Effectiveness of Engineering Group Design Projects
}

\author{
Adam Kyte \\ Plymouth University, Plymouth, UK
}

Corresponding author:

Adam Kyte, Reynolds 018, Plymouth University, Drake Circus, Plymouth PL4 8AA, UK

Email: adam.kyte@plymouth.ac.uk, Phone: + 44 (0) 1752586116

\begin{abstract}
Whilst there are many benefits of the use of Engineering Group Design Projects (EGDPs) in undergraduate engineering programmes, there are a number of common issues that can compromise their effectiveness as a learning medium. A study was carried out to identify such issues, which used creative thinking methods to identify ways in which they might be addressed. Focus was upon aligning project structure with that typical of industrial practice - a goal enhanced by the fact that the author was from an industrial rather than an academic background.
\end{abstract}

As a result, a proposed EGDP structure was developed and trialled at Plymouth University. A key feature of this structure was that the minutes of students' weekly project management meetings were recorded in a spreadsheet-based template which doubled as the project mark sheet. Each individual task recorded in the minutes was peer assessed on completion to adjust the group mark awarded by the lecturer, thus reflecting individual contributions.

The trial was a resounding success with excellent student feedback. Resulting design work was of exceptional quality, and the age-old issue of non-contributing group members was effectively eliminated.

Keywords: engineering, group, design, project, team, structure

\section{Introduction}

The author accepted a post as Lecturer in Mechanical \& Marine Engineering Design at Plymouth University (PU) a year before commencing this study. Up to this point, his involvement with academia was limited to that as a BEng and MSc student, having spent the 18 years since graduation working as a design engineer and consultant in a wide range of industry sectors (including marine, automotive, power generation and environmental engineering). In this study, educational practice was therefore viewed from the perspective of an industrialist rather than a seasoned academic. One of the author's observations was the apparent contrast between academic and industrial practice regarding Engineering 
Group Design Projects (EGDPs). Informal discussion with colleagues suggested that this was not unique to PU, but typical of EGDPs in many higher education establishments.

EGDPs are commonly used in undergraduate engineering programmes in UK universities, not least because of their favour with accreditation bodies - and for good reason. (The Engineering Council General Learning Outcomes state that "Evidence of group working and of participation in a major project is expected", and require that students' skills must include "problem solving, communication (and) working with others". (Engineering Council 2010).) EGDPs give students the opportunity to work as part of an engineering team as they will in industry. They also provide an environment in which peer learning can play a significant role, especially as class sizes increase. In fact, as student-to-staff ratios increase, lecturers find individual design projects increasingly unmanageable and group projects become the norm.

The author observed that the student approach to an EGDP was typically more of an (often last minute) report writing exercise than a genuine design activity. In addition, the design process seemed to lack much of the formal structure inherent in a well implemented industrial design project. These issues were coupled with the problems that are commonly associated with academic group project work in general, such as inaccurate assessment of individual contribution to group performance and specialisation of individuals limiting the learning outcomes for other group members (Biggs \& Tang 2007, pp219-220). These observations motivated an investigation into ways of improving EDGP structure to more effectively reap the benefits to learning that group projects should provide.

The work involved four distinct phases:

- Phase 1 - Problem definition: Identification of a concise list of EGDP issues (rather than relying on the author's subjective observations).

- Phase 2 - Ideas generation: Identifying new ways to address the issues.

- Phase 3 - Development of revised EGDP structure: Pulling the most promising ideas together to form a practical proposal for future EGDPs.

- Phase 4-Implementation and evaluation: Reflection and feedback following the first academic year in which the structure has been used.

This work involved input from colleagues, students and practising engineers. The primary aim was to align EGDP structure more closely with current industrial practice, maximising student learning of commonly used design tools/techniques through 'hands-on' experience.

The above approach would be seen as 'Action Research' by those with a pedagogic research background. It is no coincidence that this is effectively the same approach that an engineer might apply to an industrial problem: fully define the problem, brainstorm possible solutions, identify and develop the most promising idea(s) then implement and test, iterating as necessary.

\section{Background}

The EGDP is effectively a Problem/Project Based Learning (PBL) approach. PBL has "potential to increase student engagement and improve skill development" (Strobel \& van Barneveld 2009). There are many advocates of PBL in the form of EGDPs, Graham \& Crawley (2010) being one example. In many institutions, this approach now encompasses entire programmes rather than just individual modules, with the EGDP being the central core around which all the relevant engineering theory is learned, as discussed by Gibson (2001) and Hermon and McCartan (2010a). Grant et al. (2010) show that industrial involvement and an interdisciplinary approach can further increase the benefits of the EGDP. 
Many educational practitioners have faced and attempted to overcome EGDP issues. Educational literature gives some insight into such issues (and possible solutions).

Gómez Puente et al. (2011) study a wide range of engineering design project approaches in reference to the attributes that constitute "good design" as defined by Mehalik \& Schunn (2006). Denayer et al. (2003) are among the many practitioners who focus on encouraging students to follow a structured approach to EGDPs. There are, of course, as many approaches to industrial design project structure as there are authors on the subject, but one that is commonly held in high regard is the 'Total Design' method of Pugh (1990). Pugh's own experiences of implementing an industrial design approach in an academic environment (Pugh 1978) are still of interest today.

Schmidt (2006) clearly identifies the issue of specialisation preventing students from addressing areas of weakness, but offers little insight into how this issue may be practically overcome. Hermon et al. (2010a, p56) identify specialisation as "particularly evident in the area of Computer Aided Design (CAD) skills" - one student tends to do all of the CAD so the others don't improve their CAD skills. They propose two solutions: (1) Splitting CAD out into an individually assessed module and (2) Modifying EGDP assessment and Intended Learning Outcomes (ILOs) to include reward for peer mentoring, management and leadership skills, "assessed by increased supervisor observation, including use of an online project blog...".

In a subsequent paper, Hermon \& McCartan (2010b) further discuss the use of online collaboration tools for assessment, but recognise that the volume of data generated can be overwhelming for the lecturer. This could render this idea impractical for large class sizes. In the same paper, they give guidance on the use of a peer assessment scheme in which the tutor conducts a 20 minute interview with each student half way through the project to discuss their peer marks, allowing students to take corrective action where necessary. Again, this may be impractical for large class sizes. In a later paper, Hermon et al. (2010), point out the importance of using the same peer assessment system each year, so that "by year three, students know that freeloaders fail modules" (p8).

Willmot and Crawford (2007) discuss a web-based self/peer assessment tool. They show that results correlate reasonably well with 'fly-on-the-wall' mentor observations as to whether students are under- or over-performing, but not so well as to the level of under/ over-performance.

Clearly, group project output is compromised if the group loses motivation and enthusiasm. This is not unique to engineering project groups. Veil \& Turner (2002) studied project management teams and identified potential causes of loss of group motivation ('killing' ideas, overloading, static team roles and power play). They present many practical tips for avoiding these issues.

\section{Phase 1 - problem definition}

Phase 1 was concerned with objectively identifying and defining both issues and benefits associated with current EGDP module structure at PU, rather than relying on the author's subjective observations. Looking at benefits would help to ensure that restructuring would not eliminate valuable aspects of the existing structure. Data was gathered by questioning colleagues and students and by studying educational literature.

\section{Staff and student interviews}

Staff and student interviews were used as an initial open-ended means of identifying a wide range of possible issues/benefits of EGDPs. Nine interviewees were chosen to represent a 
range of role, degree programme, age, sex, academic ability and level of industrial experience.

The first part of the interview was designed to identify as comprehensive a list of issues/ benefits as possible, whilst attempting to minimise the influence of the interviewer. Consequently, open-ended questions such as "What issues do you commonly face in your EGDPs?" were used. The second, more closed part of the interview was focused on finding out whether the interviewee agreed with the observations of the author and the findings of the literature review (summarised in the Background section).

\section{Questionnaires}

As with any small-sample sized interview, there was a danger that opinions were unique to individual interviewees, rather than truly representative of the majority view of a larger sample. This issue was minimised by checking corroboration of interview results with a much larger sample size using an Audience Response System (ARS) questionnaire. Interview results were converted to a series of statements to which participants indicated their level of agreement on a five-point Likert Scale. Questionnaire results are given in Table 1.

Any statement scoring above 3.5 was deemed sufficiently representative of group opinion, and therefore worthy of inclusion in the list of EGDP issues to be addressed. Both interview and questionnaire results were used to define the lists of EGDP issues and benefits as presented in Table 2.

\section{Phase 2 - ideas generation}

Three methods were employed to generate ideas for the improvement of EGDP structure:

- Reference to the literature - what have other people done to attempt to resolve similar issues?

- Look to industry - how are EGDPs typically conducted in industry, and can industrial practice be carried over into the academic environment?

- Brainstorming of ideas - assemble a diverse range of brainstorm participants to think of as many innovative solutions as possible.

The literature review above identified many ideas upon which the brainstorm participants were then able to build.

Note: The term Brainstorm is commonly used in engineering design and many other subject disciplines to mean a methodology for generation of ideas. The term has an alternative definition referring to epileptic seizure. The National Society for Epilepsy carried out research in 2005 that concluded that use of the term in the context of ideas generation was unlikely to cause offense to sufferers of epilepsy (Epilepsy Action 2011). 
Table 1 ARS questionnaire results

\begin{tabular}{|c|c|c|c|}
\hline \multicolumn{2}{|l|}{ Statement } & $\begin{array}{c}\text { 2nd Year } \\
\text { BSc Level } \\
\text { of } \\
\text { Agreement }\end{array}$ & $\begin{array}{c}\text { Final Year } \\
\text { BEng Level } \\
\text { of } \\
\text { Agreement }\end{array}$ \\
\hline \multicolumn{2}{|c|}{$\begin{array}{l}\text { 1.) In some groups, some people "drift along" making little effort, whilst others do } \\
\text { more than their fair share of the work. }\end{array}$} & 4.11 & 4.00 \\
\hline \multicolumn{2}{|c|}{$\begin{array}{l}\text { 2.) The reason some people feel they can get away with little contribution is that it is } \\
\text { difficult for the marker to assess the contribution of individuals }\end{array}$} & 4.07 & 3.57 \\
\hline \multicolumn{2}{|c|}{$\begin{array}{l}\text { 3.) Current peer assessment methods are not fully effective in determining the } \\
\text { contribution of individuals and distributing marks accordingly }\end{array}$} & 3.48 & 3.71 \\
\hline \multirow{2}{*}{$\begin{array}{l}\text { 4.) Group Design Projects tend to lack the formal design process } \\
\text { structure that would normally be followed in industry }\end{array}$} & 1st Yr EGDPs & 3.38 & \multirow{2}{*}{4.07} \\
\hline & 2nd Yr EGDPs & 2.70 & \\
\hline \multirow{2}{*}{$\begin{array}{l}\text { 5.) Students tend to put off working on EGDPs because of other } \\
\text { deadlines, so EGDPs become a last minute report writing exercise } \\
\text { rather than an iterative design process. }\end{array}$} & 1st Yr EGDPs & 3.77 & \multirow{2}{*}{4.07} \\
\hline & 2nd Yr EGDPs & 3.42 & \\
\hline \multicolumn{2}{|c|}{$\begin{array}{l}\text { 6.) Most people do the tasks that they are good at in group design projects, which } \\
\text { means they don't get better at the things they are not good at. }\end{array}$} & 3.93 & 3.86 \\
\hline \multicolumn{2}{|c|}{$\begin{array}{l}\text { 7.) Some people put too much time into group design projects, which means they } \\
\text { don't spend enough time on other modules. }\end{array}$} & 2.85 & 3.21 \\
\hline \multicolumn{2}{|c|}{$\begin{array}{l}\text { 8.) Regular feedback on your group design work is important, otherwise you only find } \\
\text { out if you have done things wrong when the final report is marked. }\end{array}$} & 4.37 & 4.50 \\
\hline \multicolumn{2}{|c|}{$\begin{array}{l}\text { 9.) In group design modules, it is difficult to find a time when all group members are } \\
\text { available for a meeting. }\end{array}$} & 3.93 & 4.29 \\
\hline \multirow{2}{*}{$\begin{array}{l}\text { 10.) In some modules, the marking scheme is poorly defined, } \\
\text { making it difficult to know what is required. }\end{array}$} & 1st Yr EGDPs & 3.40 & \multirow{2}{*}{4.71} \\
\hline & 2nd Yr EGDPs & 1.89 & \\
\hline \multicolumn{2}{|c|}{$\begin{array}{l}\text { 11.) It is unfair to appoint a chairperson to be in charge of the group when all group } \\
\text { members are at the same educationalexperience level }\end{array}$} & 2.63 & 2.71 \\
\hline \multicolumn{2}{|c|}{$\begin{array}{l}\text { 12.) Many group design projects do not allow for sufficient creativity or invention - } \\
\text { they are simply a re-engineering of an existing product }\end{array}$} & 3.27 & 3.93 \\
\hline \multicolumn{2}{|c|}{$\begin{array}{l}\text { 13.) Some students can get through group design projects without having to do much } \\
\text { calculation }\end{array}$} & 4.11 & 4.29 \\
\hline \multicolumn{2}{|c|}{$\begin{array}{l}\text { 14.) Some students can get through group design projects without showing any } \\
\text { creativity or inventiveness }\end{array}$} & 4.00 & 4.64 \\
\hline \multicolumn{2}{|c|}{$\begin{array}{l}\text { 15.) All group members learn to present their work verbally and in writing by doing } \\
\text { group design projects. }\end{array}$} & 2.96 & 3.71 \\
\hline \multicolumn{2}{|c|}{$\begin{array}{l}\text { 16.) It is not possible to get through a group design project without learning to work } \\
\text { as a member of a team }\end{array}$} & 3.12 & 2.57 \\
\hline
\end{tabular}

Notes:

1. Level of agreement is based on a 5-point Likert Scale i.e.:

- Score of 5 - entire group strongly agree with the statement

- Score of 1 - entire group strongly disagree with the statement

- Score of 3 - group were neutral, or opinion was evenly split (or a combination of both).

2. Two cohorts completed the questionnaire: 2 nd Year BSc (27 participants from a cohort of 49) \& Final Year BEng (14 participants from a cohort of 29).

3. For some questions, BSc students gave answers specific to the EGDPs they had done in their 1st or 2 nd year. This was to assess the effect of changes to 2 nd year EGDP structure that had already been trialled in the year preceding this study. These changes were:

- to place extra emphasis on the importance of engineering design process structure

- to impose (voluntary) intermediate project deadlines

- to create more detailed, transparent assessment criteria

Inspection of the table above suggests that whilst these changes have had some favourable effect, there is still considerable room for further improvement. 
Table 2 Issues and benefits associated with Engineering Group Design Projects

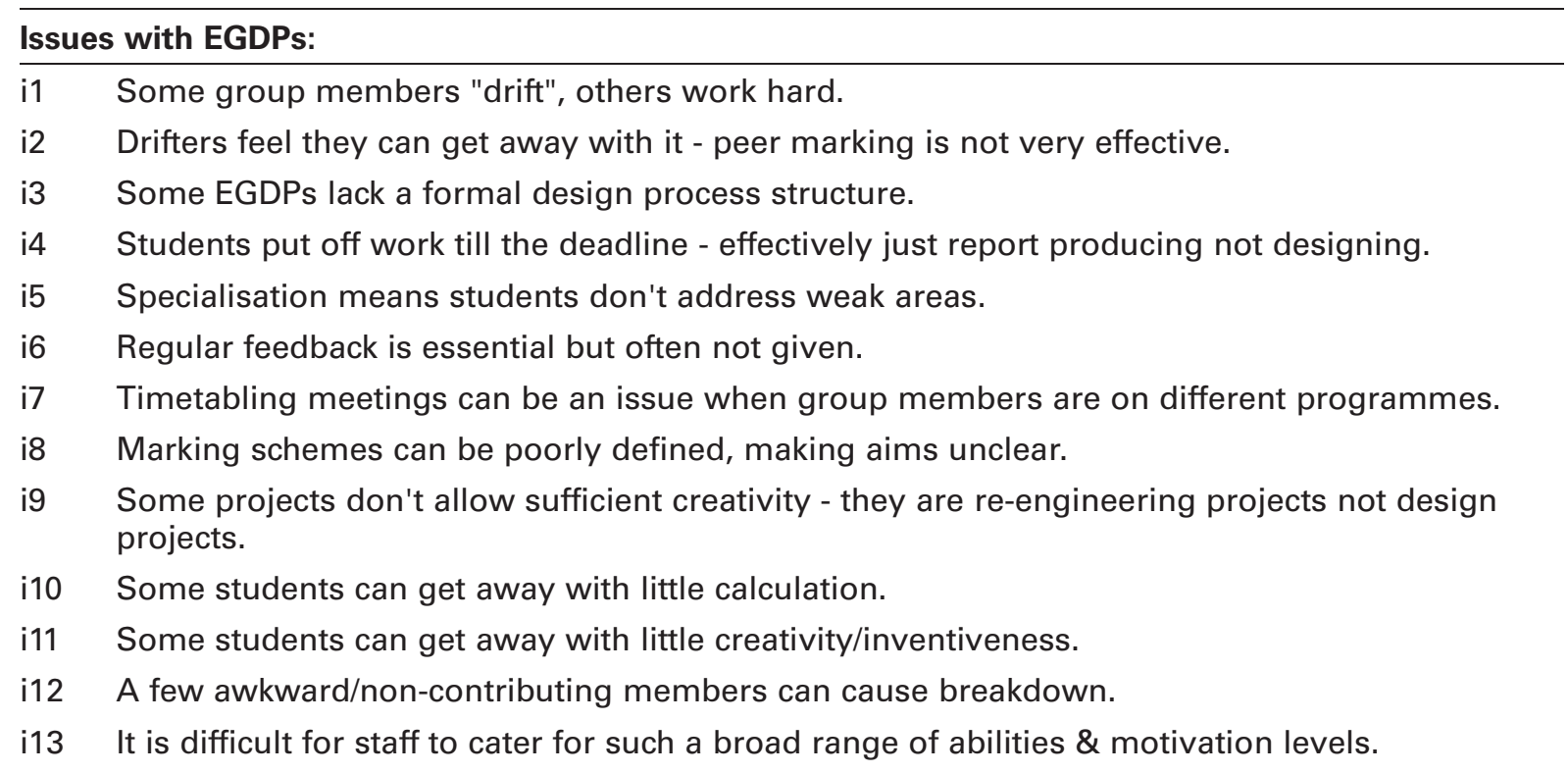

\section{Benefits of EGDPs over individual design assignmets:}

b1 Can be representative of the way design work is done in industry.

b2 Increase the breadth and depth of design task that can be tackled.

b3 Develop team working, interpersonal skills, project management \& conflict resolution.

b4 Provide a wide range of different skills, experience, ideas \& opinions within the group.

b5 Can promote peer learning (benefiting both the learner and teacher).

b6 Can promote interdisciplinary awareness and interaction.

b7 Required for accreditation - drawing together all other engineering modules.

b8 Reduction of assessment load for lecturer.

b9 Output can be greater than the sum of the individual contributions.

b10 Forces students to work outside their comfort zone.

Note: i1 to i11 were drawn from collated questionnaires. i12 \& i13 were drawn from staff interview, as staff were not involved in questionnaires. Both staff and student interviews were used to generate b1 to b10.

\section{Industrial interviews}

The investigation into industrial practice was carried out by telephone interview. Four interviewees were chosen; a naval architect (defence industry), an automotive engineer, a Formula 1 engineer and a pumping/fluids handling engineer. Rather than comprehensively analysing industrial practice, the interviews were simply aimed at generating thoughtprovoking material to be input into the brainstorming process for further ideas to be built upon. Interviewees were asked how EGDPs are structured within their companies, and what issues arise as a result. Useful output included the following:

- A formal meeting structure can drive industrial EGDPs; projects may feature initial, (weekly) interim and completion meetings. Company policy dictates some standard agenda items in such meetings.

- Drawings and calculations, etc. are usually generated by one person, checked by another, and signed off by a third. 
- Companies enforce a structure for adequate recording of decisions, calculations, drawings, meeting minutes, etc., to ensure ISO 9000 series quality approval.

- Roles within a design team are usually assigned according to subsystems of the device being designed.

- It seems that lack of effort of a group member is a problem largely confined to academic rather than industrial projects. On the occasions when this does happen in industry, close supervision and/or disciplinary procedure are common practice, with employment terminated if there is no improvement.

- A 'tell someone if you have problems' culture helps to spot project issues early, allowing timely resource redistribution/contingency to take place.

\section{Brainstorming session}

Brainstorming was used as the main ideas generation technique; if done competently it is a method that generally produces a rich selection of novel, relevant solutions to a given problem statement. (Whilst brainstorming is a common activity in many subject disciplines, its effectiveness can vary considerably depending on the way it is structured and facilitated. www.brainstorming.co.uk gives useful guidance on maximising the productivity of a brainstorm session.) The brainstorm participants (ten in total) were the same staff and students who had been interviewed previously, plus a visiting engineering design lecturer from the USA. The problem statement was to "Think of ways to address the issues identified with current EGDP structure whilst maintaining current benefits". The list of issues/benefits (Table 2) was displayed in the room for reference.

The brainstorm generated a wide range of innovative ideas, which were then ranked to generate a shortlist of ideas worthy of implementation. Most shortlisted ideas were ultimately incorporated into the structure developed in Phase 3.

\section{Phase 3 - development of revised EGDP structure}

Using the brainstorm output, the author drafted a framework for an EGDP structure initially intended for final year engineering design modules (but applicable to lower years with some adjustment/simplification). This structure contained proposed project timeline, marking scheme, assessment criteria and level descriptors, assignment brief, supporting software and a presentation to explain this structure to staff and students.

The structure was presented to colleagues and iteratively revised in light of their feedback. Key features of the resulting EGDP structure are summarised below. Text in italics explains the logic behind each point. Numbers in curved brackets $\{i X\}$ refer to the item from Table 2 being addressed:

1. Students are split into design teams, each team consisting of three groups of five or six members (group size representative of that typically reported by the industrial interviewees). Such group sizes ensure that project management is sufficiently challenging \{i3\} whilst limiting the opportunity for group members to 'hide' $\{i 1\},\{i 2\}$. Requirement for groups to interface with the other two groups within their team is again representative of typical of industrial practice, and further encourages structured project management $\{i 3\}$. Note that smaller group sizes and stand-alone groups would be recommended for EGDPs in lower years to avoid overwhelming students with less advanced project management skills.

2. Teams are given a design brief against which to develop a design solution, with each group within the team tasked with a specific aspect of that brief. Deliverables are split into a series of three staged deadlines: 
- Deadline 1:

O Project introduction and development of full Product Design Specification.

o Five concept design sketches from each group member.

- Deadline 2:

O Brainstorm to develop (then shortlist) design concepts.

O Basic calculations to estimate feasibility of concepts.

o Brief risk assessment to identify potential pitfalls/issues with concepts.

○ Logical selection of the most promising concept.

- Deadline 3:

O All other deliverables to take design from concept to completed design. Deliverables will be project specific, but may include research into relevant engineering principles, calculations, CAD modelling/drawing, selection of materials/manufacturing processes, numerical simulation, physical experiments, etc.

$\circ$ Evaluation of the resulting design and design process/group dynamics.

This encourages early engagement $\{i 4\}$ and use of a formal design process structure $\{i 3\}$. Work presented for each deadline is marked soon after it is submitted, which spreads out marking load and provides timely guidance and feedback $\{i 6\}$.

3. The Deadline 3 deliverables (and their assessment criteria/mark scheme weightings) are defined in negotiation between students and lecturer after Deadline 2. This is because every design project is different; the design development/completion activities will vary considerably between projects. The negotiated mark scheme encourages planning and structure $\{i 3\}$ - "What steps will lead us to a successful design?".

4. Weekly project meetings are conducted and recorded on a standard minutes template in spreadsheet form (see Figure 1). The minutes spreadsheet also forms the mark sheet for the project. In it, groups record tasks allocated to each member and, in subsequent project meetings, democratically peer assess the standard to which those tasks have been performed. The spreadsheet automatically 'locks down' the minutes of the previous week, so students can't adjust agreed task definitions to match the work that has actually been completed. This is intended to add project management structure $\{i 3\}$, and make peer assessment less subjective $\{i 2\}$, with a clear connection between non/poor completion of tasks and low peer assessment marks $\{i 1\},\{i 2\}$. It also aims to reduce procrastination throughout the year $\{i 4\}$.

5. When assigning tasks, the group agree an estimate of the number of hours that each task should take. Tasks are then evenly distributed between the individual group members. On completion of a task, the spreadsheet automatically records a 'score' for that task, calculated by multiplying the estimated hours by two adjustment factors: one related to the peer assessment of the task, and one dependent on whether the task was completed on time (see Figure 1). The spreadsheet records the cumulative score for each student. The lecturer marks the overall outcome of the project against well-defined marking criteria. The cumulative 'score' that each group member has amassed over the project duration is then used to individually adjust that individual's mark up or down using a peer adjustment formula. This is done to help students learn to estimate task durations (essential in industrial projects). It also aims to ensure that the cumulative score adequately rewards the quantity, quality and timeliness of the tasks that a student completes. Basing the score on a pre-agreed task duration estimate aims to avoid situations where students boost their score by exaggerating the number of actual hours actually spent on the task. 


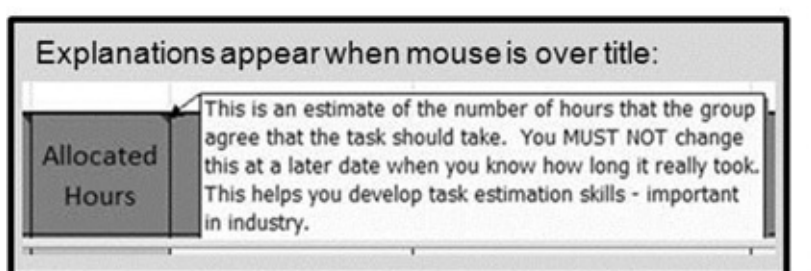

Score for each task is automatically calculated, so in this case:

Allocated Hours (6)

$x$ Completion factor ( 0.75 for " 1 week late") $x$ Quality factor ( 0.3 for "Poor attempt at task")

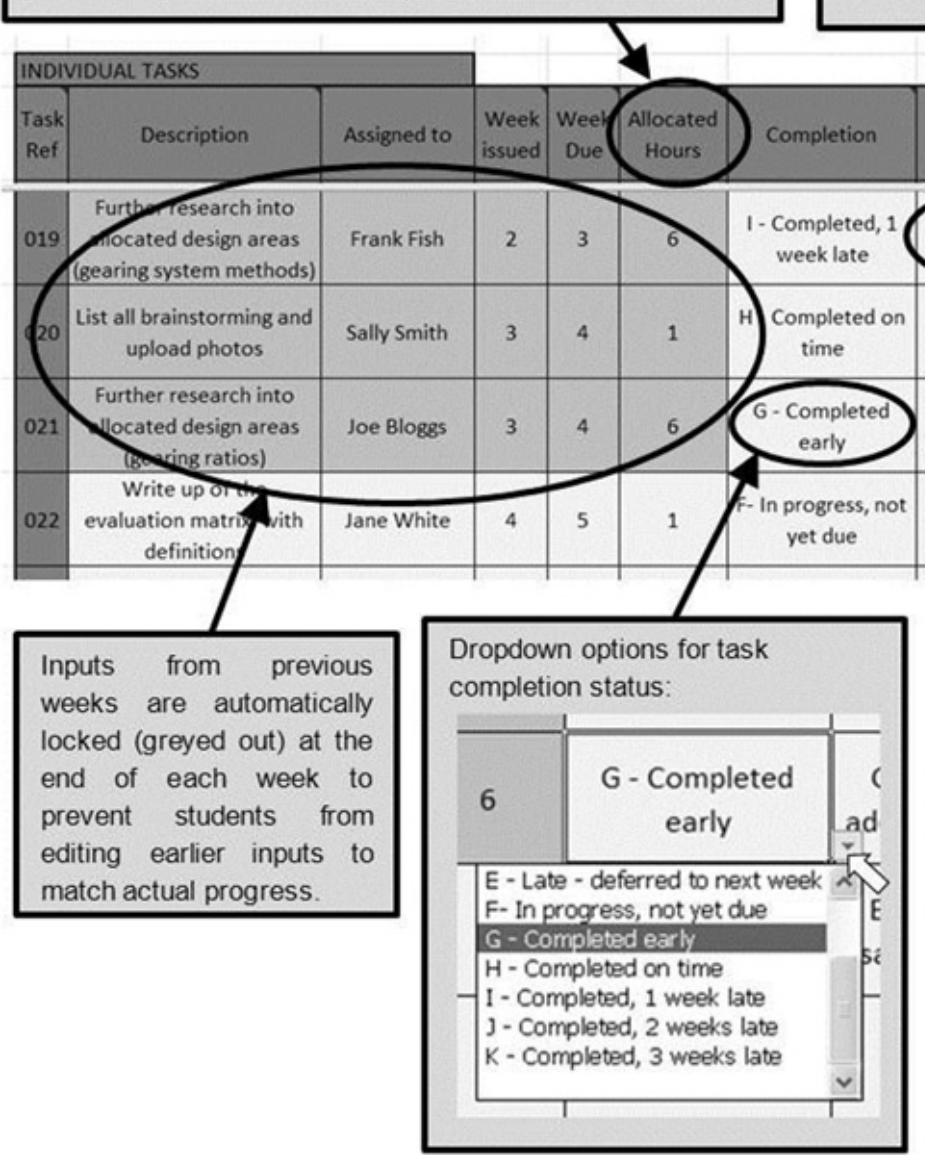

Figure 1 Typical minutes/mark sheet content. Note that this image only shows the individual tasks part of the spreadsheet. Other areas deal with meeting agenda/minutes/attendance, group tasks, Gantt chart and marking (with lecturer feedback).

6. Some tasks (such as a brainstorming or selection of the best design concept) feature in almost every design project, and must involve the entire group. In such cases, the lecturer marks the outcome of that specific group task. The group democratically peer assess the contribution of each member to that group task, adjusting the individual mark for that task up or down. This is to reward engagement in group tasks.

7. There are some tasks that all students must carry out individually. These include:

- Producing a sheet of initial design concepts (for subsequent use in the group brainstorm).

- Calculations to assess the feasibility of one design concept.

- Evaluation of the design and design process/group dynamics.

These tasks are marked individually by the lecturer and are not subject to any form of peer assessment. This is to reduce the issue of specialisation $\{i 5\}$ and ensure that all 
students must do some tasks that involve creativity $\{i 11\}$ and calculation $\{i 10\}$. It also aims to reduce the impact of peer assessment problems $\{i 2\}$ and reduce 'drifting' $\{i 1\}$.

8. Calculations are carried out using a three-step process: calculation, checking and sign-off (as in most engineering companies). One student does the calculation, one checks/corrects it as required, then they both 'sign off' an agreed final version. The calculation is presented on a formal calculation sheet template. This is designed to provide some structure and industrial relevance $\{i 3\}$, and promotes peer learning and interaction.

9. The secretary (i.e. minute taker) role is rotated each meeting, and minutes are marked - so each student gets chance to take minutes. Again, reduces specialisation $\{i 5\}$.

10. EGDP modules have weekly timetabled project meetings, and also timetabled project time for group tasks to be carried out. This is to avoid issues with students on different programmes being unable to find times when all are available $\{i 7\}$.

11. The lecturer visits each group in turn during their timetabled project meeting, to provide feedback and check on the validity of the information entered into the minutes. Reduces opportunity to drift $\{i 1\},\{i 2\}$, and provides essential, timely guidance and feedback $\{i 6\}$.

12. A Project Manager is elected to manage progress meetings and take responsibility for the Gantt chart, which is updated weekly and included as part of the minutes spreadsheet. The spreadsheet automatically saves a 'locked' version of the previous week's Gantt chart, so it cannot be retrospectively changed to match proposed and actual progress. Allowance is made in the task scoring system to credit the project manager for his/her time spent on project management. This approach aims to add project management structure $\{i 3\}$ and encourage regular project progress $\{i 4\}$.

13. The marking scheme and level descriptors have been clearly defined and constructively aligned (Biggs \& Tang 2007) with module Intended Leaning Outcomes driven by Engineering Council requirements (Engineering Council 2010), \{i8\}. The marking scheme can be seen in Table 3.

14. The marking scheme includes areas where marks are awarded for viability of the final design, creativity/innovation, problem solving and iteration. This is to reward groups that adopt a holistic design approach, focused on a high quality outcome (rather than just a 'mechanical' progression through a linear series of design process steps).

15. Wherever possible EGDPs involve real tasks defined by a real 'client', such as a company or member of the public. Students are encouraged to interact with that client throughout the project. This is to encourage customer-focused design, and increase student motivation levels.

\section{Phase 4 - implementation and evaluation}

The structure developed in Phase 3 was implemented in the 30 credit Engineering Design \& Computational Methods module for a full cohort of BEng final year students. The EGDP was a 16 credit assignment carried out in Term 2, so was to represent just over a quarter of the students' Term 2 course commitments. As regular contact with EGDP groups was a key feature of the assignment structure, the author (as module leader) was able to monitor the process and gather constant feedback.

The task used to test the new EGDP structure was the design of a streamlined handcycle - an arm-powered cycle for use by a paraplegic, aimed at beating the world handcycle speed record of $45.68 \mathrm{mph}$. This was a 'real-world' task, as it was set by a 
Table 3 Project marking scheme

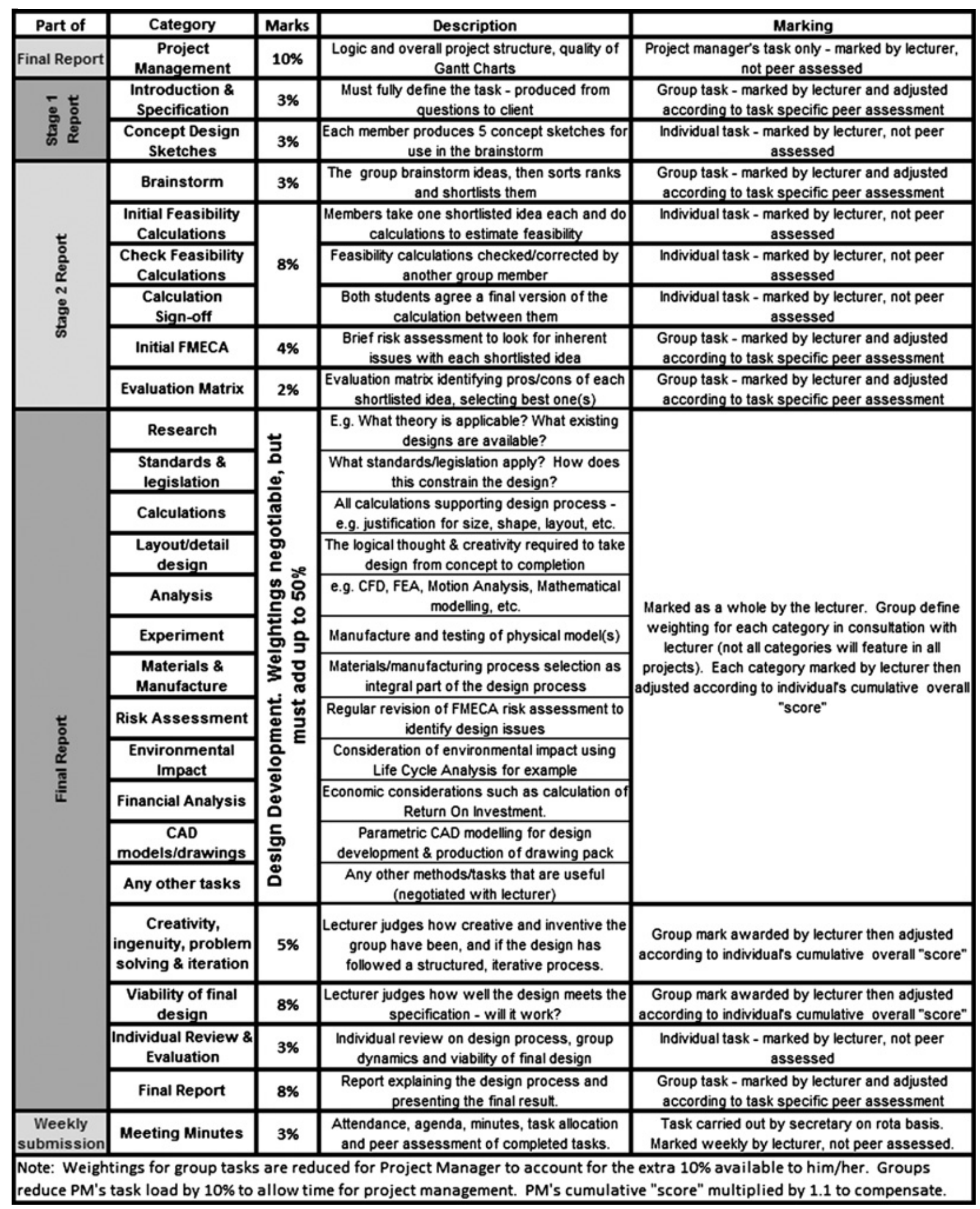

disabled athlete who had contacted PU for assistance in developing the cycle. Students maintained regular contact with the athlete throughout the project.

Students were split into two competing teams, each team consisting of three groups. In each team, one group was responsible for the design of the streamlined body shell, one for the drive mechanism and the other for the frame. This meant that students not only had to 
work with the other members of their group, they also had to work with the other groups in their team (just as they would in an interdisciplinary design project in industry). Figures 2 and 3 show images of the device that one of the teams designed. Statistical analysis of the assignment marks is given in Table 4.

\section{What went well}

- Implementation was, in general, a resounding success, as can be seen from the feedback later in this paper.

- The minutes/mark sheet spreadsheet system worked very well. The spreadsheet contained a considerable amount of Visual Basic for Applications (VBA) code that effectively automated much of the functionality, and made the input required from users (students and lecturer) very straightforward. The author's initial reservations about the complexity of the mark scheme and peer assessment scheme proved largely unfounded as the spreadsheet automated the application of both of these schemes.

- Students engaged throughout the duration of the project - much more so than in the EGDPs that the author observed in previous years.

- The problem of underperforming or non-contributing group members was almost eliminated, apparently due to the direct, clear connection between adequate completion of assigned tasks and final individual mark. The automatic marks adjustments resulting from the peer marking scheme were generally small (typically one or two percent, with 27 of the 33 students awarded marks within four percent of their group average). Whilst this can be due to low weighting of peer adjustments or reluctance of group members to award low peer marks to underperforming colleagues, neither was the case here. The fact that adjustments were small seems due to the fact that the system achieved its aim in motivating full engagement of all group members, rather than just 'catching' those who did not engage.

- Peer marking schemes where students can affect each other's marks can be controversial, but this was not an issue here. Peer assessment on a task-by-task basis (rather than overall peer marking of relative contributions at the end of the project) removed much of the subjectivity, and was done democratically in each group with no complaints.

- Students did follow the kind of structured design approach typical of industrial EGDPs, and the quality of the designs that they ultimately produced was exceptional as a result.

- The mechanisms for feedback from the lecturer were timely enough for students to learn from mistakes and implement this new knowledge.

- Any problems with group dynamics and non-contributing group members were identified and rectified in the first few weeks of the project. A brief discussion between lecturer and group members during project meetings was all that was required to resolve such issues; once individuals realised that the lecturer was aware of the situation, contribution dramatically improved.

- Students learned as much about project management and teamwork as they did about the engineering itself. The requirement for groups to coordinate design activity with that of the other groups within their team proved especially challenging and was probably the aspect that triggered the steepest learning curve!

- All of the issues in Table 2 were addressed to a large extent, whilst all of the benefits listed were maintained (and in many cases enhanced). 


\section{What did not go so well}

- The calculate/check/sign-off system for calculations proved too long-winded, both for students and for the lecturer when marking. Students also generally just checked 'if the sums were right', rather than 'had the right sums been used', limiting the effectiveness of the checking exercise. On reflection, the complexity of the calculate/check/sign-off system outweighs potential benefits and it will not be used in future years.

- The minutes/mark sheet spreadsheets relied on the VBA macros for their functionality. Students were therefore told that on opening the spreadsheet, they must 'enable macros' in response to any security warning pop-ups. Not doing so caused spreadsheet errors that the lecturer had to repeatedly repair. This could be overcome by making the minutes/mark sheet a custom-built application, rather than a macro-enabled spreadsheet.

- There was no specific Stage 1 deliverable covering research. Consequently, students tried to develop concept designs before researching the necessary engineering science. For example, the development of streamlined geometry concepts requires a basic understanding of relevant fluid mechanics. Stage 1 deliverables will be updated to include research in future.

- Whilst students universally agreed that the revised EGDP structure was a substantial improvement over their first and second year EGDPs, they said it was a big step to adapt from what they were used to. Work is now underway to ensure that Years 1 and 2 build up the appropriate holistic approach to design work and awareness of relevant design tools/techniques.

- No marks were allocated for the integration of each individual group's design work with that of the other groups in their team. As a result, some of their designs did not 'fit together' as well as they could have done. In future, marks will be awarded for both team performance and group performance.

- Students found the module very demanding and time consuming - colleagues suggested that in some cases, engagement in other modules may have suffered as a result. This is an unwanted bi-product of the success of the EGDP (with students' natural tendency towards spending time on work that they find enjoyable, productive and rewarding). It may be necessary to select a simpler design task in future. An analysis to determine which aspects of the project are most time consuming will be carried out, to see where workload could be reduced. As an example, students carry out Failure Mode, Effects and Criticality Analysis (FMECA) in their design process; a time consuming task if hundreds of failure modes are identified. Limiting the number of failure modes to ten may not significantly affect understanding of the FMECA process, but would substantially reduce workload.

\section{What the students said}

Feedback was obtained through standard PU Module Review forms, through extensive informal verbal student feedback and from the EGDP project reports, where each student wrote a brief personal summary/evaluation of their group project. Although largely qualitative, this showed the approach to have been a resounding success, with around 95 percent of the feedback being positive. The students nominated their lecturer for the Student Union's 'Most Inspirational Teaching' award on the strength of this assignment. A sample of student feedback is given below:

This design project has been the single most useful thing I have done at University. 


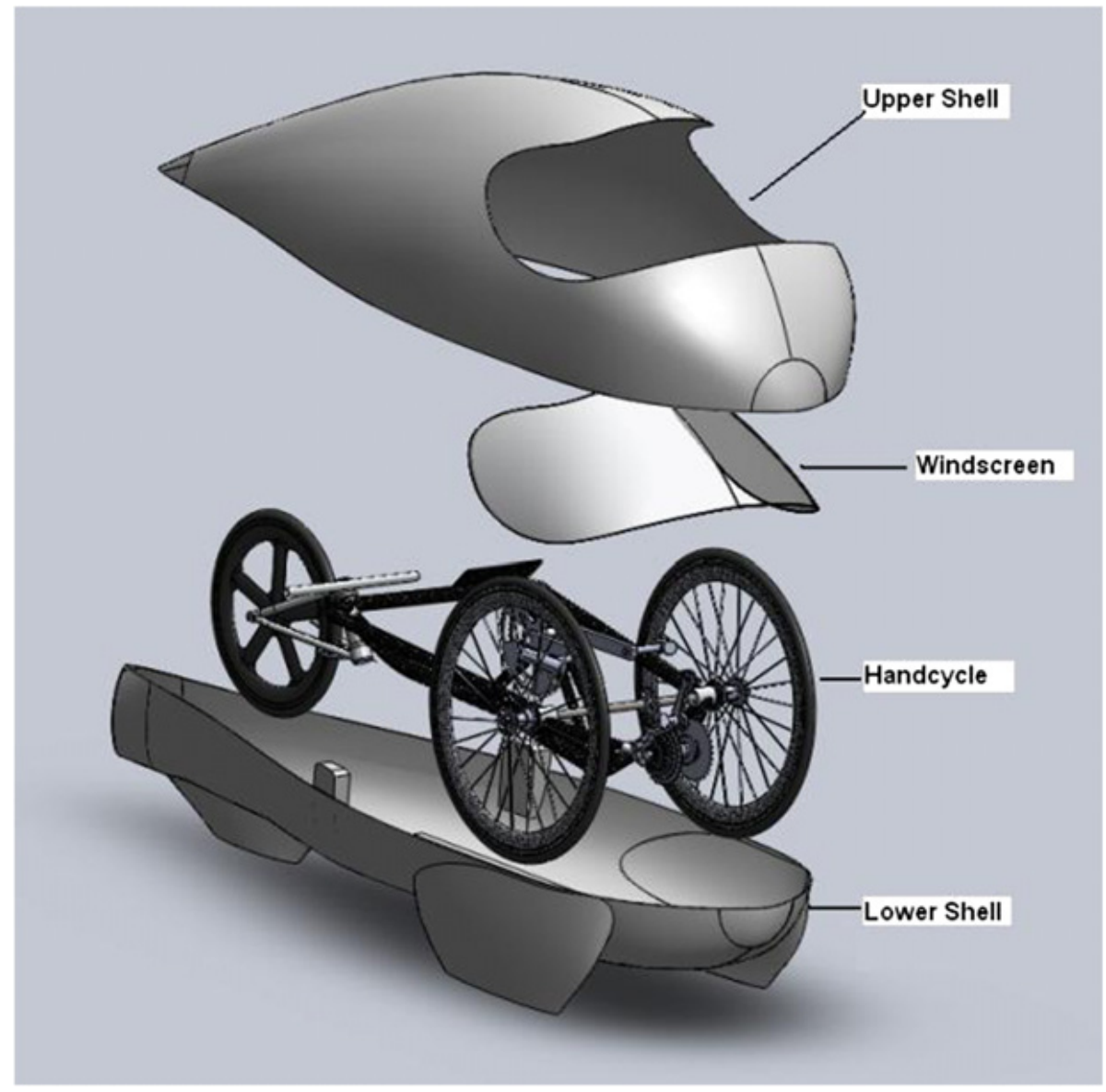

Figure 2 Exploded view of the handcycle

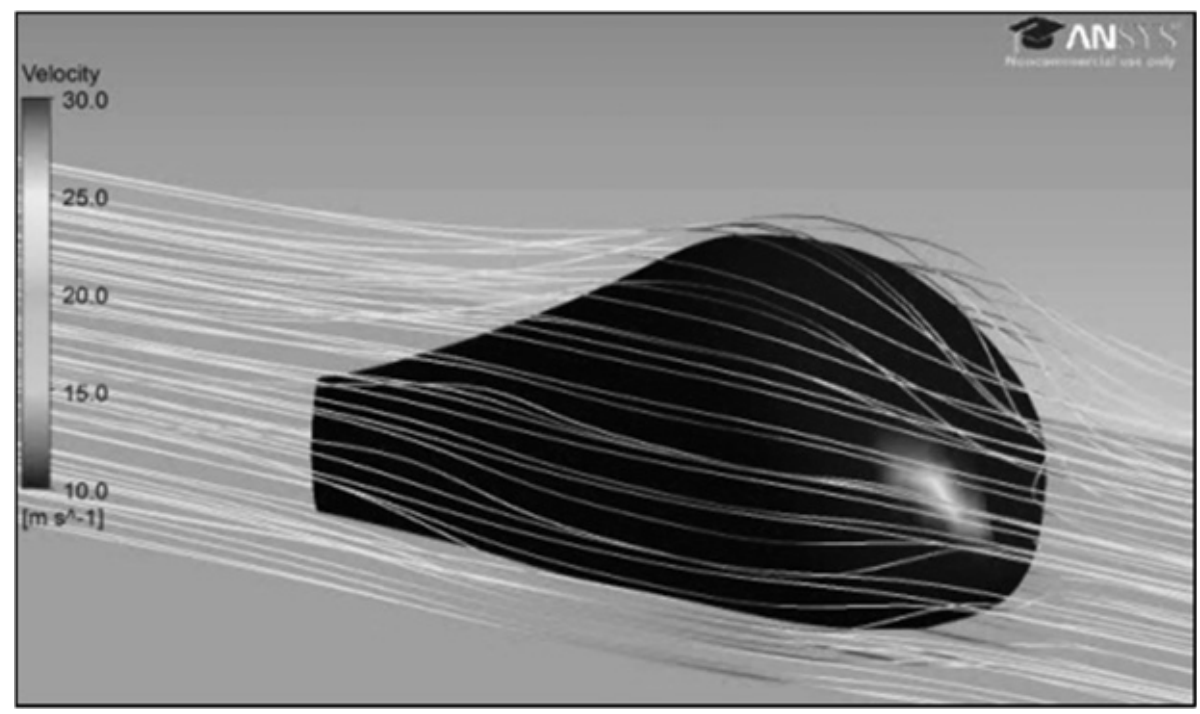

Figure 3 Computational Fluid Dynamics simulation of the handcycle 
Table 4 Assignment mark statistics

\begin{tabular}{ll}
\hline Number of students & 33 \\
\hline Mean mark & 63.65 \\
Standard deviation & 6.45 \\
Mark & Number of students \\
0 to 40 & 0 \\
40 to 50 & 2 \\
50 to 60 & 4 \\
60 to 70 & 21 \\
70 to 80 & 6 \\
80 to 100 & 0 \\
\hline
\end{tabular}

I believe that the design followed an iterative, systematic approach. I feel we all learned a lot about the actual process of design and integrating continuous improvement to optimise final results.

The report was very easy to write due to the fact that the design work had already been done - it just needed to be documented.

The minutes/mark sheet template system ensured that some work was done in every week throughout the project, which took the pressure off towards the end and ensured that we could get the information requested by the other groups in our team quickly.

The advantages of this project included the chance to be creative whilst using engineering design principles and developing design skills.

All in all everyone pulled their weight (a rarity in group design modules) and it was a superb effort by everyone.

Fantastic module, but lots of work - it did take a bit of a toll on marks in other modules.

In terms of our design and design process, I truly believe that we have, as a group, carried out what seems to be a rigorous and iterative design process, through extensive research, quantitative experimental work, communication and liaison with the other groups and through logical, effective engineering thinking. We have, through blood, sweat and not that many tears, come up with a fully working design which will be, in my opinion, able to break the world record if it is ever built.

I learnt more in eight or nine weeks than I did in the previous three years of design modules put together.

The group design was hectic, but felt like I was actually doing something realistic, rather than repeating a 20 -year-old exercise.

The External Examiner made the following comment in his report when asked to identify areas of good practice and innovation relating to learning, teaching and assessment in the school: 
The continuous self-assessment of the team design projects is innovative and proves very effective; an excellent approach that removes the problem of students not engaging with the project work.

\section{Conclusions}

This paper has shown that the Action Research approach to analysing and restructuring Engineering Group Design Projects at Plymouth University has resulted in a step change in the effectiveness of such projects as a learning mechanism. It has given students an excellent insight into the way they may eventually work within an industrial design team, and has helped them to learn to follow a structured, logical approach to design work. Problems with lack of engagement in group design projects have been almost eliminated; student satisfaction has risen and the quality of design work produced as a result has dramatically improved.

Probably the most significant feature of the new scheme is the fact that meeting minutes double as the project mark sheet, meaning that every task that a student carries out is peer assessed and contributes to their overall mark. In the early stages of the project, this provides the incentive to engage. By the end of the project, students are so enthused that job satisfaction alone seems sufficient to motivate full engagement.

Feedback and reflection on the first year of using the new scheme in a final year module have been used to propose possible future improvements, thus entering the next iteration of the development process (i.e. the next Action Research cycle). Expanding the revised EGDP approach to modules in Years 1 and 2 is expected to reap further benefits; it will hopefully ensure that competence in applying a logical and well-managed approach to group design work is second nature to students by the time they reach their final year.

\section{References}

Biggs, J. and Tang, C. (2007) Teaching for quality learning at university, 3rd edn. Maidenhead: Open University Press.

Denayer, I., Thaels, K., Vander Sloten, J. and Gobin, R. (2003) Teaching a structured approach to the design process for undergraduate engineering students by problem based education. European Journal of Engineering Education 28 (2), 203-214.

Engineering Council (2010) The accreditation of higher education programmes. Available at http://www.engc.org.uk/ecukdocuments/internet/document\%20library/AHEP\%20Brochure. pdf (accessed 13 June 11).

Epilepsy Action (2011). Is the word 'brainstorming' offensive to people with epilepsy? available online at http://www.epilepsy.org.uk/press/facts/brainstorming-offensive (accessed 13 June 2011).

Gibson, I. (2001) Group project work in engineering design - learning goals and their assessment. International Journal of Engineering Education 17 (3), 261-266.

Gómez Puente, S.M., van Eijck, M. and Jochems, W. (2011) Towards characterising design-based learning in engineering education: a review of the literature. European Journal of Engineering Education 36 (2), 137-149.

Graham, R. and Crawley, E. (2010) Making projects work: a review of transferable best practice approaches to engineering project based learning in the UK. Engineering Education $5(2), 41-49$. 
Grant, P., Macpherson, E., Harrison, G., Brunson, K., Hyde, R., and Williams, D. (2010) Teaching integrated system design with interdisciplinary group design exercises. Engineering Education 5 (1), 30-41.

Hermon, P., McCartan, C. and Cunningham, G. (2010) Group design-build-test projects as the core of an integrated curriculum in product design and development. Engineering Education 5 (2), 50-58.

Hermon, P. and McCartan, C. (2010a) Assessing the softer skills learning outcomes in group projects. Presented at $3^{\text {rd }}$ International Symposium for Engineering Education, 2010, University College Cork, Ireland.

Hermon, P. and McCartan, C. (2010b) Assessing the development of personal and professional skills in group projects. Presented at $6^{\text {th }}$ International CDIO Conference, 2010. École Polytechnique, Montréal.

Loddington, S. (2008) Peer assessment of group work: a review of the literature. Part of a project led by the Faculty of Engineering, University of Loughborough as part of the JISC eLearning Capital Programme. Available at http://webpaproject.lboro.ac.uk/files/ WebPA_Literature\%20review\%20.pdf (accessed 10 August 2011).

Mehalik, M.M. and Schunn, C. (2006) What constitutes good design? A review of empirical studies of design processes. International Journal of Engineering Education 22 (3), 519-532.

Pugh, S. (1978) Engineering design education - with real life problems. European Journal of Engineering Education 3 (1), 135-147.

Pugh, S. (1990) Total design: integrated methods for successful product engineering. Addison-Wesley.

Schmidt, L.C. (2006) Engineering teams: individual or group sport? International Journal of Engineering Education 22 (3), 659-664.

Strobel, J. and van Barneveld, A. (2009) When is PBL more effective? A meta-synthesis of meta-analyses comparing PBL to conventional classrooms. The Interdisciplinary Journal of Problem Based Learning 3 (1), 44-58.

Willmot, P. and Crawford, A. (2007) Peer review of team marks using a web-based tool: an evaluation. Engineering Education 2 (1), 59-66.

Veil, C. and Turner, J.R. (2002) Group efficiency improvement: how to liberate energy in project groups. International Journal of Project Management 20, 137-142. 